\title{
Study on the Factors Influencing Total Health Cost Based on Multiple Regression Model
}

\section{Xiaoduo Zu, Jun Fang}

Institute of Finance and Public Management, Anhui University of Finance and Economics, Bengbu 233000, Anhui, China DOI: $10.32629 /$ memf.v2i6.596

\begin{abstract}
In recent years, China's social economy and income level of residents have increased rapidly, the total cost of health has increased rapidly, and the level of medical expenditure of residents has been increasing. This paper establishes a multivariate linear regression model using data from 1996 to 2020, and analyzes several important influencing factors that affect overall health expenditure. The aim is to formulate a health financing policy suitable for the coordinated development of China's social economy, and to provide a basis for adapting to the needs of economic development, structural adjustment and institutional transformation.
\end{abstract}

Keywords: total cost of health, influencing factors, regression analysis

\section{Build the data}

Table 1. Total health costs and related variables

\begin{tabular}{|c|c|c|c|c|}
\hline Year & $\begin{array}{l}\text { Total health costs ( } 100 \\
\text { million yuan) } \\
\text { Y }\end{array}$ & $\begin{array}{c}\text { Number of beds in health } \\
\text { facilities }(10,000) \\
\mathrm{X}_{1}\end{array}$ & $\begin{array}{c}\text { Birth rate }(\%) \\
\mathrm{X}_{2}\end{array}$ & $\begin{array}{c}\text { Utilization rate of beds in } \\
\text { township hospitals (\%) } \\
X_{3}\end{array}$ \\
\hline 1996 & 2709.42 & 309.96 & 16.98 & 37 \\
\hline 1997 & 3196.71 & 313.45 & 16.57 & 34.5 \\
\hline 1998 & 3678.72 & 314.3 & 15.64 & 33.3 \\
\hline 1999 & 4047.5 & 315.9 & 14.64 & 32.8 \\
\hline 2000 & 4586.63 & 317.7 & 14.03 & 33.2 \\
\hline 2001 & 5025.93 & 320.12 & 13.38 & 31.3 \\
\hline 2002 & 5790.03 & 313.61 & 12.86 & 34.7 \\
\hline 2003 & 6584.1 & 316.4 & 12.41 & 36.2 \\
\hline 2004 & 7590.29 & 326.84 & 12.29 & 37.1 \\
\hline 2005 & 8659.91 & 336.75 & 12.4 & 37.7 \\
\hline 2006 & 9843.34 & 351.18 & 12.09 & 39.4 \\
\hline 2007 & 11573.97 & 370.11 & 12.1 & 48.4 \\
\hline 2008 & 14535.4 & 403.87 & 12.14 & 55.8 \\
\hline 2009 & 17541.92 & 441.66 & 11.95 & 60.7 \\
\hline 2010 & 19980.39 & 478.68 & 11.9 & 59 \\
\hline 2011 & 24345.91 & 515.99 & 11.93 & 58.1 \\
\hline 2012 & 28119 & 572.48 & 12.1 & 62.1 \\
\hline 2013 & 31668.95 & 618.19 & 12.08 & 62.8 \\
\hline 2014 & 35312.4 & 660.12 & 12.37 & 60.5 \\
\hline 2015 & 40974.64 & 701.52 & 12.07 & 59.9 \\
\hline 2016 & 46344.88 & 741.05 & 12.95 & 60.6 \\
\hline 2017 & 52598.28 & 794.03 & 12.43 & 61.3 \\
\hline 2018 & 59121.91 & 840.40 & 10.86 & 59.6 \\
\hline 2019 & 65841.39 & 880.70 & 10.41 & 57.5 \\
\hline 2020 & 72306.40 & 910.10 & 8.5 & 53.6 \\
\hline
\end{tabular}

Source: China Statistical Yearbook (1996-2020), official website of the China Bureau of Statistics 


\section{Regression analysis}

In the SPSS software, using the multi-linear regression model for analysis, the original data is linearly regressed in all 3 arguments in SPSS, and the output result is as Table 2.

As can be seen from the table of direct regression coefficients, the number of beds in health institutions, the birth rate of the population and the utilization rate of the beds in township hospitals are all less than 10, which is explains that there is no significant multiple collinearity between them.

Table 2. Table of direct regression coefficients ${ }^{\mathrm{a}}$

\begin{tabular}{|c|c|c|c|c|c|c|c|c|}
\hline & \multirow{2}{*}{ Model } & \multicolumn{2}{|c|}{ Unstandardized Coefficients } & \multirow{2}{*}{$\begin{array}{c}\begin{array}{c}\text { Standardized } \\
\text { Coefficients }\end{array} \\
\text { Beta }\end{array}$} & \multirow{2}{*}{$\mathrm{t}$} & \multirow{2}{*}{ Sig. } & \multicolumn{2}{|c|}{ Collinearity Statistics } \\
\hline & & B & Std. Error & & & & Tolerance & VIF \\
\hline \multirow[t]{4}{*}{1} & (Constant) & -12616.504 & 3597.132 & & -5.719 & .003 & & \\
\hline & $\begin{array}{l}X_{1} \text { Number of beds in health } \\
\text { facilities }(10,000)\end{array}$ & 96.370 & 3.082 & 1.016 & 36.776 & .000 & .256 & 3.907 \\
\hline & $\mathrm{X}_{2}$ Birth Rate (\%o) & -726.813 & 207.392 & -.073 & -6.833 & .003 & .626 & 1.597 \\
\hline & $\begin{array}{l}\mathrm{X}_{3} \text { Utilization rate of beds in } \\
\text { township hospitals }(\%)\end{array}$ & -73.906 & 44.247 & -.061 & .143 & .112 & .204 & 4.891 \\
\hline
\end{tabular}

a. Variable: Total health costs Y (100 million yuan)

Table 3. Table of ANOVA ${ }^{b}$

\begin{tabular}{|c|c|c|c|c|c|c|}
\hline \multicolumn{7}{|c|}{ ANOVA } \\
\hline \multicolumn{2}{|c|}{ Model } & \multirow{2}{*}{$\begin{array}{c}\text { Sum of Squares } \\
4.924 \mathrm{E} 9\end{array}$} & \multirow{2}{*}{$\frac{\mathrm{df}}{2}$} & \multirow{2}{*}{$\begin{array}{c}\text { Mean Square } \\
2.462 \mathrm{E} 9\end{array}$} & \multirow{2}{*}{$\begin{array}{c}\mathrm{F} \\
1.682 \mathrm{E} 3\end{array}$} & \multirow{2}{*}{$\begin{array}{l}\text { Sig. } \\
.000 \mathrm{a}\end{array}$} \\
\hline 1 & Regression & & & & & \\
\hline & Residual & $2.782 \mathrm{E} 7$ & 19 & 1464087.912 & & \\
\hline & Total & 4.952E9 & 21 & & & \\
\hline
\end{tabular}

a. Predictors: (Constant), $X_{2}$ Birth rate (per thousand), $X_{1}$ Number of beds in health facilities $(10,000)$

b. Dependent Variable: Total health costs Y (100 million yuan)

As can be seen from Table 3, F is $1.682 \mathrm{E} 3$ and the $\mathrm{P}$ value is close to 0 , indicating that the regression equation is significant, and that the number of beds in health facilities and the birth rate have a significant linear effect on the total cost of health.

$$
\mathrm{Y}=-16347.335+92.114 x_{1}-562.073 x_{2}
$$

\section{Policy recommendations}

Based on the results of the above regression analysis,the following recommendations are made.

\subsection{Raise the level of economic development and coordinate the relationship between individuals and society}

Total health cost financing and the affordability of the composition affecting economic development, the development of health care and the disease economy burden, if the individual resident's health expenditure is too high will increase the economic burden of the resident's disease, resulting in "expensive medical care" and "causes". Disease leads to poverty, "the problem, without universal health then there will be no comprehensive (well-off. Socially, with the reform of China's financial system and medical and health system, the allocation of medical and health resources is gradually becoming more and more (commercial and market-oriented China's supply entities are pursuing market interests, and their dependence on market demand is gradually increasing. On the other hand, health services have gradually evolved into private goods, leading to the gradual withdrawal of government and social resources investment from the dominant position, and the gradual increase in individual health expenditure the important component of health expenditure, which is when the proportion of personal health expenditure gradually decreases and the proportion of social health expenditure gradually increases.It shows that social groups, charities and some social health institutions are helping residents with their medical services it has played a role in reducing the pressure on some residents to pay for health care, and the level of per capita funding has increased.The 
proportion of the social care system in the entire health care fund-raising structure.

\subsection{Improve the level of health financing and optimize the allocation and use of health costs}

On the one hand, China is facing a new economic normal, maintaining economic growth and appropriately expanding its fiscal deficit in stages.To raise the level of total health expenditure, on the other hand, to optimize the structure of government and social health expenditure, increase government health insurance expenditure and social health expenditure, social health insurance expenditure. The structure of social health expenditure in social health expenditure also needs to be optimized. The growth of the total population will undoubtedly lead to the consumption of various resources, health and health care resources will inevitably increase, and thus lead to. The increase in the total cost of health, now the level of medical care in our society is slowly improving, a variety of diseases that were previously incurable. (Most are now treatable and become common diseases that can be cured by surgery and medication, and most residents typically spend more on health care.)

\subsection{Continue to increase government investment in health and promote China's health construction}

China is in the final stage of building a well-off society in an all-round way and deepening medical reform,however, there is still a big gap between the level of health invested by the Chinese government and the developed countries of the world, in accordance with the "one outline, two plans" proposed "to establish results-oriented health input mechanism", "to establish a fair and effective sustainable financing system" under the requirements of the goal, whether now or in the future every period must be We will continue to increase the direction of government investment in health, promote the medical reform, a project that the people attach great importance to, and take important measures on the economy, all of which contribute to the construction of a healthy China.

\subsection{Take preventive measures in a timely manner to (avoid the rapid growth of health costs}

China's comprehensive strength in all aspects is constantly increasing, and the city is constantly developing. In terms of population, the number of young people is decreasing and the number of elderly people is increasing. The types of people's illnesses are also constantly changing. In the future, social health expenditures must increase unabated. In order to promote the steady and reasonable growth of health expenditures and ensure the realization of the goals of medical reform and cost control, a scientific prevention and detection system must be established. We must always pay attention to the development of health expenditure and improve the governance level of health development. Time should be adjusted according to the situation in a timely manner. At the same time, it is not possible to unilaterally pursue the maximization of benefits to cause excessive increase in health expenses, and not to make urban and rural people feel an excessive economic burden.

\section{References}

[1] Li Xiangrong, Tang Wei, Zhang Chenxuan, Ma Wei. Analysis of the factors influencing the total cost of health in China. Health Soft Science, 2018(01).

[2] Wang Dan, Guan Xiaoguang, Yu Xueping. Research and analysis of the health service situation in China. Chinese Medicine Guide, 2018(06).

[3] Chen Chunyan, The current situation of public health expenditure of our government and the countermeasure research. Yunnan University of Finance and Economics, 2018(05).

[4] Sun Shujun. The relationship between health spending, people's health and economic growth. Shenyang Pharmaceutical University, 2018(05).

[5] Li Yan, Zhang Weihui, Wan Quan, et al. Results and Analysis of China's Total Health Expenses accounting for 2016. China Health Economy, 2018(05).

[6] Wang Gaoling, Zhang Yiqing. Based on the ARIMA model, the trend and composition of China's total health costs are predicted and analyzed. China Health Statistics, 2019(02).

[7] Ma Xinmei. Analysis of the investment of health expenses in China over the past ten years. Economist, 2018(04).

[8] Wen Jie, Du Fuxuan, Li Liqing, Lu Zuxuan. The influencing factors and empirical research of china's total health cost. General Medicine of China, 2016(02).

[9] Yang Yue, Liu Junlan, Teng Haiying, Xiong Linping. The progress of health cost analysis and its enlightenment to the accounting of health cost in China. China Health Management, 2015(03).

[10] He Ruibo, Yin Xiaolu, Liu Qiuxu, Li Junshan. Empirical research and predictive analysis of the factors influencing the total cost of health in China. China Health Economy, 2015(04).

[11] Hong Ting. Regression Analysis of The Main Components of the Total Health Cost Influencers in Guangdong Province. Health Soft Science, 2015(12).

[12] Gao Zhifang. Empirical analysis of the factors influencing the total cost of health in China. Business, 2016, (32): 70. 
[13] Wang Chaoyang, Xiao Hui. Research on the forecast and influencing factors of total health cost in Hubei Province. Medicine and Society, 2020, 33(10): 11-15, 25.

[14] Gao Yu, Zhang Bei, Gao Qianqian, Jing Qi, Sheng Hongqi, Ma Guifeng, Ma Anning, Cai Weiqin. Study on the Changes of Influencing Factors of my country's Total Health Expenditure before and after the New Medical Reform. Chinese Health Economics, 2020, 39(08): 39-41. 